Gugushvili, N., Täht, K., Rozgonjuk, D., Raudlam, M., Ruiter, R. \& Verduyn, P. (2020). Two dimensions of problematic smartphone use mediate the relationship between fear of missing out and emotional well-being. Cyberpsychology: Journal of Psychosocial Research on Cyberspace, 14(2), Article 3. https://doi.org/10.5817/CP20202-3

\title{
Two Dimensions of Problematic Smartphone Use Mediate the Relationship Between Fear of Missing Out and Emotional Well-Being
}

\author{
Nino Gugushvili1 ${ }^{1}$, Karin Täht ${ }^{1}$, Dmitri Rozgonjuk ${ }^{1}{ }^{3}$, Maris Raudlam¹, Robert Ruiter ${ }^{2}$, \& Philippe Verduyn $^{2}$ \\ 1 University of Tartu, Tartu, Estonia \\ ${ }^{2}$ Maastricht University, Maastricht, Netherlands \\ 3 Ulm University, Ulm, Germany
}

\begin{abstract}
It has been shown that both fear of missing out (FoMO) and problematic (i.e., excessive) smartphone use (PSU) are negatively associated with indicators of emotional well-being. Moreover, FoMO has been found to be a key predictor of PSU. This suggests that PSU may mediate the relation between FoMO and decreased emotional wellbeing but this pathway has never been tested. Moreover, in most studies on PSU, the multidimensional nature of this construct has been ignored. The aim of the present study was to address these gaps by directly testing the mediating role of (subdimensions of) PSU in the association between FoMO and emotional well-being. We conducted a cross-sectional study with Estonian participants $(n=426)$. Using a simple mediation analysis, we found that PSU partially mediated the relationship between FOMO and decreased emotional well-being. Using a parallel mediation analysis, we found that two specific dimensions of PSU were significant mediators of the relationship between FoMO and decreased emotional well-being: Cyberspace-oriented Relations and Physical Symptoms. This suggests that the negative relationship between FoMO and decreased emotional well-being is due to FoMO stimulating (a) online relationships at the cost of offline interactions and (b) Physical symptoms associated with excessive smartphone use. Overall, this study provides a fine-grained analysis of the relationship between FOMO, PSU and emotional well-being.
\end{abstract}

Keywords: Fear of missing out; problematic smartphone use; emotional well-being; cyberspace-oriented relationships; physical symptoms

Please note: Article updated on May 28, 2020. The figures 3 and 4 were updated. The figures incorrectly displayed positive direct ( $c^{\prime}$ ) and total effect (c) of FoMO on emotional well-being. The effects should have been negative and were now corrected. In Figure $3{ }^{\prime \prime}{ }^{\prime} c^{\prime}=.455^{\prime \prime}$ and ${ }^{\prime} c=.638^{\prime \prime}$ was changed to " $c^{\prime}=-.455^{\prime \prime}$ and " $c=-.638^{\prime \prime}$. In Figure 4 , ${ }^{\prime \prime} \mathrm{C}^{\prime}=.508^{\prime \prime}$ and ${ }^{\prime} \mathrm{C}=.640$ " was changed to " $\mathrm{C}^{\prime}=-.508^{\prime \prime}$ and " $\mathrm{C}=-.640$. The error occurred during formatting of the figures by the journal.

\section{Introduction}

Shortly after the introduction of smartphones on the global market, their ownership has increased drastically (Poushter et al., 2018). Currently, more than two billion people possess a smartphone (Takahashi, 2018) and they spend on average nearly three hours on their smartphone each day using it for accessing social network sites, 
watching videos, shopping and searching information amongst others (ComScore, 2017; Ofcom, 2018). These compact devices offer important benefits to users in various domains, including healthcare (Camacho et al., 2014), education (Godwin-Jones, 2011), and social communication (Chan, 2015).

However, smartphone usage may also have negative consequences. Specifically, excessive smartphone usage, often labeled in the literature as problematic smartphone use (PSU), is associated with negative outcomes such as decreased productivity (Duke \& Montag, 2017), low academic achievement and distraction from the learning process (Lepp et al., 2014; Rozgonjuk, Kattago, et al., 2018; Rozgonjuk, Saal, et al., 2018; Samaha \& Hawi, 2016), and low quality communication in social settings (Vanden Abeele et al., 2016). Perhaps most importantly, PSU has also been found to be associated with decreased mental health and emotional well-being (Elhai et al., 2019; Elhai, Tiamiyu, et al., 2018; Rozgonjuk, Levine, et al., 2018).

PSU is predicted by a wide range of individual characteristics including age and personality traits (Blackwell et al., 2017; Hussain et al., 2017). One person-characteristic that has consistently been found to be a predictor of PSU is fear of missing out (FoMO) (Alt, 2015; Błachnio \& Przepiórka, 2018; Dhir et al., 2018; Scott \& Woods, 2018). Moreover, both FoMO (Baker et al., 2016; Elhai et al., 2020; Milyavskaya et al., 2018; Reer et al., 2019; Tsai et al., 2019) and PSU are directly linked to decreased emotional well-being (Augner \& Hacker, 2012; Demirci et al., 2015; Harwood et al., 2014; Smetaniuk, 2014).

This pattern of findings suggests that PSU may mediate the relationship between FoMO and emotional well-being. However, this mediation pathway has never been directly tested. Moreover, despite that PSU is well-known to be a multidimensional construct (Ching et al., 2015; Kwon et al., 2013; Rozgonjuk et al., 2016), it is typically studied as a one-dimensional construct. As such, it is not clear which subdimensions of PSU are the key mediators explaining the relationship between FoMO and emotional well-being.

The aim of the present study was to address these gaps by directly testing the mediating role of (subdimensions of) PSU in the association between FoMO and emotional well-being. This is important as this increases our understanding of person-level risk factors that drive problematic usage of smartphones and associated negative emotional consequences. Moreover, the present study is directly relevant for the growing public concern regarding FoMO and PSU (Barkan, 2019; Barker, 2016; Brueck \& S. Lee, 2018; Twenge, 2019) which is addressed in national (Canadian Paediatric Society, 2017; Chassiakos et al., 2016; Davie \& Firth, 2019) and international guidelines (World Health Organization, 2019). As such, the present study is a direct response to calls for "more and better research" to facilitate the development of evidence-based evaluation, prevention and intervention tools (Ashton \& Beattie, 2019; Davie \& Firth, 2019).

To realize our study aims, we conducted a cross-sectional study and ran simple and parallel mediation analyses to test whether (subdimensions of) PSU mediate the relationship between FoMO and emotional well-being. We tested this pathway in a sample of Estonian participants. It is notable that Estonia is one of the technologically most advanced and digitalized societies worldwide (Heller, 2017) with $88 \%$ of Estonian residents using the internet on a daily basis and $73 \%$ of them accessing the internet via smartphones (Statistics Estonia, 2018).

In the next sections, we will first define and discuss the three key constructs of the present manuscript in more detail: FoMO, PSU, and emotional well-being. Next, we will discuss the relationship between these constructs on a theoretical and empirical level. Finally, the specific goals and hypotheses of the present study will be described.

\section{Key Constructs}

\section{Fear of Missing Out (FoMO)}

FoMO refers to the "pervasive apprehension that others might be having rewarding experiences from which one is absent" (Przybylski et al., 2013, p. 1841). FoMO has been predominantly explored in digital settings where it has been related to problematic usage of technologies including smartphones, social network sites, and the internet more generally (Chotpitayasunondh \& Douglas, 2016; Oberst et al., 2017; Wolniewicz et al., 2018). It is assumed that one of the main characteristics of FoMO is the urge to constantly keep in touch and monitor what other friends are doing (Przybylski et al., 2013). 
Browne and colleagues (2018) reported various socio-emotional correlates of FoMO including negative affect, rejection sensitivity, and high stress levels. Moreover, FoMO has been found to be associated with a wide range of unsatisfied psychological needs including basic needs such as autonomy (i.e., the intrinsic need for volition), competence (i.e., the intrinsic need to be efficient in one's environment), relatedness (i.e., the intrinsic need for interpersonal connections) (Przybylski et al., 2013; Xie et al., 2018), and need for approval (Browne et al., 2018; Lai et al., 2016).

\section{Problematic Smartphone Use (PSU)}

PSU is defined as the excessive use of smartphone devices, which significantly disturbs and interferes with everyday life (Billieux, Maurage, et al., 2015). Moreover, PSU is often conceptualized within the frame of addiction models (Billieux, Philippot, et al., 2015). Specifically, it is assumed that it shares many similarities with other types of behavioral addictions but is less acute than addiction disorders (Panova \& Carbonell, 2018).

It is notable that in addition to PSU, several other terms have been used to refer to excessive smartphone use including smartphone overuse (Ding \& Li, 2017; Inal et al., 2015), smartphone addiction (Kwon et al., 2013; Lin et al., 2014), smartphone addiction proneness (D. Kim et al., 2014) or simply excessive smartphone use (Chen et al., 2016). However, to avoid confusion, we will use the term problematic smartphone use (PSU) consistently throughout the paper as proposed by Panova and Carbonell (2018).

PSU consists of several dimensions (Ching et al., 2015; Kwon et al., 2013): (a) Tolerance - the constant need to use a smartphone and the inability to control usage of the device; (b) Positive Anticipation - the presence of overly positive expectations about smartphone use, such as having fun or alleviating boredom; (c) Cyberspace-oriented Relationships - the preference for online friendships over face-to-face friendships; (d) Withdrawal - states of impatience, irritation and negative affect when being interrupted during smartphone usage; (e) Physical Symptoms - also known as the daily-life disturbance dimension referring to feelings of exhaustion, lack of sleep and neck pain caused by the overuse of smartphones (Kwon et al., 2013; Rozgonjuk et al., 2016).

\section{Emotional Well-Being}

Emotional well-being is defined as "a composite of positive affect and negative affect that ebbs and flows and has a momentary character reflecting a person's emotional status quo at any given time" (Eid \& Larsen, 2008, p. 259). High levels of emotional well-being consist of low levels of negative affective states, such as depressive mood, anger, sadness, or anxiety, and high levels of positive affective states, such as joy, fascination, happiness, optimism, or cheerfulness (Fredrickson \& Joiner, 2002; Kahneman \& Deaton, 2010). People also differ in trait-levels of emotional well-being as reflected by inter-individual differences in average levels of positive and negative affect (Fredrickson \& Joiner, 2002; Larsen, 2009).

High levels of emotional well-being imply that people feel good, which in and of itself is an important outcome. However, emotional well-being is also associated with other crucial outcomes such as increased physical health (Lamers et al., 2012) or productivity (Oswald et al., 2015), which further underscores the importance of research on determinants of emotional well-being. Finally, it is notable that emotional well-being is a key component of the broader construct of subjective well-being (Larsen, 2009).

Recent research investigating the relation between digital communication and subjective well-being has increasingly focused on this emotional aspect of subjective well-being. For example, there is cross-sectional and longitudinal evidence indicating that emotional well-being is associated with and affected by usage of modern technologies, such as smartphones and social network sites and the nature of this association is negative (Contractor et al., 2017; H.-J. Kim et al., 2019; Verduyn et al., 2015). Psychological mechanisms such as negative social comparisons (Verduyn et al., 2017), envy (Tandoc et al., 2015), boredom (Elhai, Vasquez, et al., 2018) and sleep disturbance (Lemola et al., 2015) have been proposed to explain the negative associations between digital screen usage and emotional well-being. 


\section{The Relation Between the Key Constructs}

\section{The I-PACE Model}

In order to explain why some people engage in technology usage and why it sometimes further develops into problematic behavior, we make us of the Interaction of Person - Affect - Cognition - Execution (I-PACE) model of behavioral addictions (Brand et al., 2019).

I-PACE was originally developed as a framework to understand the development and maintenance processes of specific internet-use addictions (Brand et al., 2016), but due to the similarities with problematic usage patterns of technologies, it has been extended to research on problematic social media use (Kircaburun et al., 2020) and problematic use of smartphones as well (Duke \& Montag, 2017) such that nowadays the model is being used in the context of a wide range of modern technologies (Brand et al., 2019).

The I-PACE model assumes that the development of problematic smartphone use is a multileveled process, preceded by certain psychological and neurobiological factors that underlie and eventually drive individuals to problematic usage. Wegmann et al. (2017) have suggested that the trait FoMO is one of such antecedents. Moreover, the I-PACE model posits that consequences from heavy usage of technology include negative long-term impacts for global well-being, such as losing control over behavior, loneliness, isolation, and conflicts (Brand et al., 2016, 2019).

\section{Empirical Findings}

The path between FoMO and PSU as suggested by the I-PACE model is empirically well established. In crosssectional and experimental studies, positive connections have been found between FoMO and general and problematic types of smartphone usage (Adelhardt et al., 2018; Elhai et al., 2016; Elhai, Levine, et al., 2018; Franchina et al., 2018). However, it is noteworthy that in all these studies PSU was examined as a unidimensional construct. Moreover, there is ample evidence which indicates that FoMO is directly and significantly associated with many adverse outcomes, including diminished emotional well-being (Burnell et al., 2019; Wolniewicz et al., 2020), and life satisfaction (Błachnio \& Przepiórka, 2018; Przybylski et al., 2013).

Similarly, a considerable body of literature has examined the path from PSU to negative psychological outcomes, as also hypothesized by the I-PACE model. Specifically, two recent systematic reviews demonstrate that PSU is consistently associated with diminished emotional well-being (Elhai, Dvorak, et al., 2017; Vahedi \& Saiphoo, 2018). Moreover, PSU is related to social anxiety (E. B. Lee, 2015; Y.-K. Lee et al., 2014), sleep problems and stress as well (Lemola et al., 2015; Thomée et al., 2011). Thus, empirical findings are in accordance with the I-PACE model.

In most of these studies PSU was examined as a unidimensional construct but in a number of studies, the relation between specific dimensions of PSU and various indicators of subjective well-being, including emotional wellbeing, has also been examined. While social anxiety was found to be related to all dimensions of PSU (Darcin et al., 2015), other studies indicate that relationships may be dimension specific. Specifically, a study by S. Lee and colleagues (2018) demonstrated a positive relation between the dimension "Cyberspace-oriented Relationships" and interpersonal competence. In contrast, Darcin and colleagues (2015) found that this dimension was positively related to higher levels of loneliness. There is also evidence that there is a positive relation between the dimension "Positive Anticipation" of PSU and non-social usage of smartphones (Elhai, Hall, et al., 2017), which in turn is associated with decreased emotional well-being (Elhai, Levine, et al., 2017). As such, first evidence is available that the relation between PSU and outcome variables may differ across PSU dimensions.

\section{The Present Study}

Addressing the limitations of prior research, in the present study we examine whether (subdimensions of) PSU mediate the relation between FoMO and emotional well-being. First, we will investigate whether PSU mediates the relationship between FoMO and diminished emotional well-being, treating PSU as a unidimensional construct (see Figure 1). Second, we will employ a more fine-grained approach and examine which dimension(s) of PSU mediate the relation between FoMO and emotional well-being, treating PSU as a multidimensional construct (see Figure 2). 
It is notable that we will specifically focus on negative indicators of emotional well-being, as negative affective states impact overall emotional well-being more strongly than positive ones (Eid \& Larsen, 2008). Based on the previous empirical findings and the theoretical assumptions of the I-PACE model we expect that:

$\mathrm{H} 1$ : FoMO positively predicts (subdimensions of) PSU. This hypothesis is based on previous research indicating that FoMO is positively related to the overuse of social media (Franchina et al., 2018) and smartphones (Chotpitayasunondh \& Douglas, 2016).

$\mathrm{H} 2$ : FoMO predicts diminished emotional well-being. This hypothesis is based on prior studies demonstrating a significant negative relation between FoMO and various indicators of overall well-being (Błachnio \& Przepiórka, 2018; Przybylski et al., 2013).

H3: (Subdimensions of) PSU predicts diminished emotional well-being. There is already substantial evidence that links PSU to decreased emotional well-being (Elhai, Dvorak, et al., 2017; Vahedi \& Saiphoo, 2018).

H4: (Subdimensions of) PSU mediate the association between FoMO and decreased emotional well-being. This mediation path has never been tested directly before but, relatedly, Dhir and colleagues (2018) found that the relation between FoMO and negative affective outcomes, such as social media fatigue, was indirect and mediated by overuse of social media.

We will test the mediating role of specific dimensions of PSU in an exploratory manner as previous research on specific dimensions of PSU has yielded mixed results (Darcin et al., 2015; S. Lee et al., 2018). We, therefore, formulate the following research question:

RQ1: Which dimension(s) of PSU mediate the relationship between FoMO and emotional well-being?

To test our hypotheses, we conducted a cross-sectional study asking participants to complete standard questionnaires assessing our key constructs: FoMO, PSU, and emotional well-being.

Figure 1. Conceptual Model of Relation Between FoMO and Emotional Well-Being Mediated by PSU (Unidimensional).

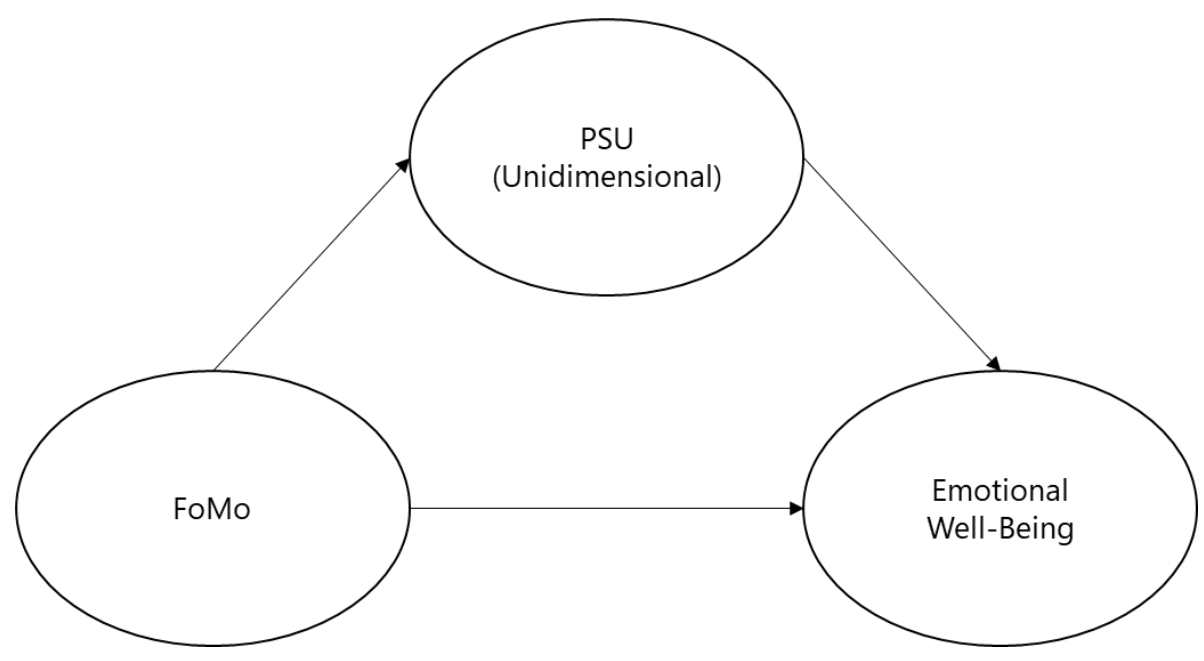




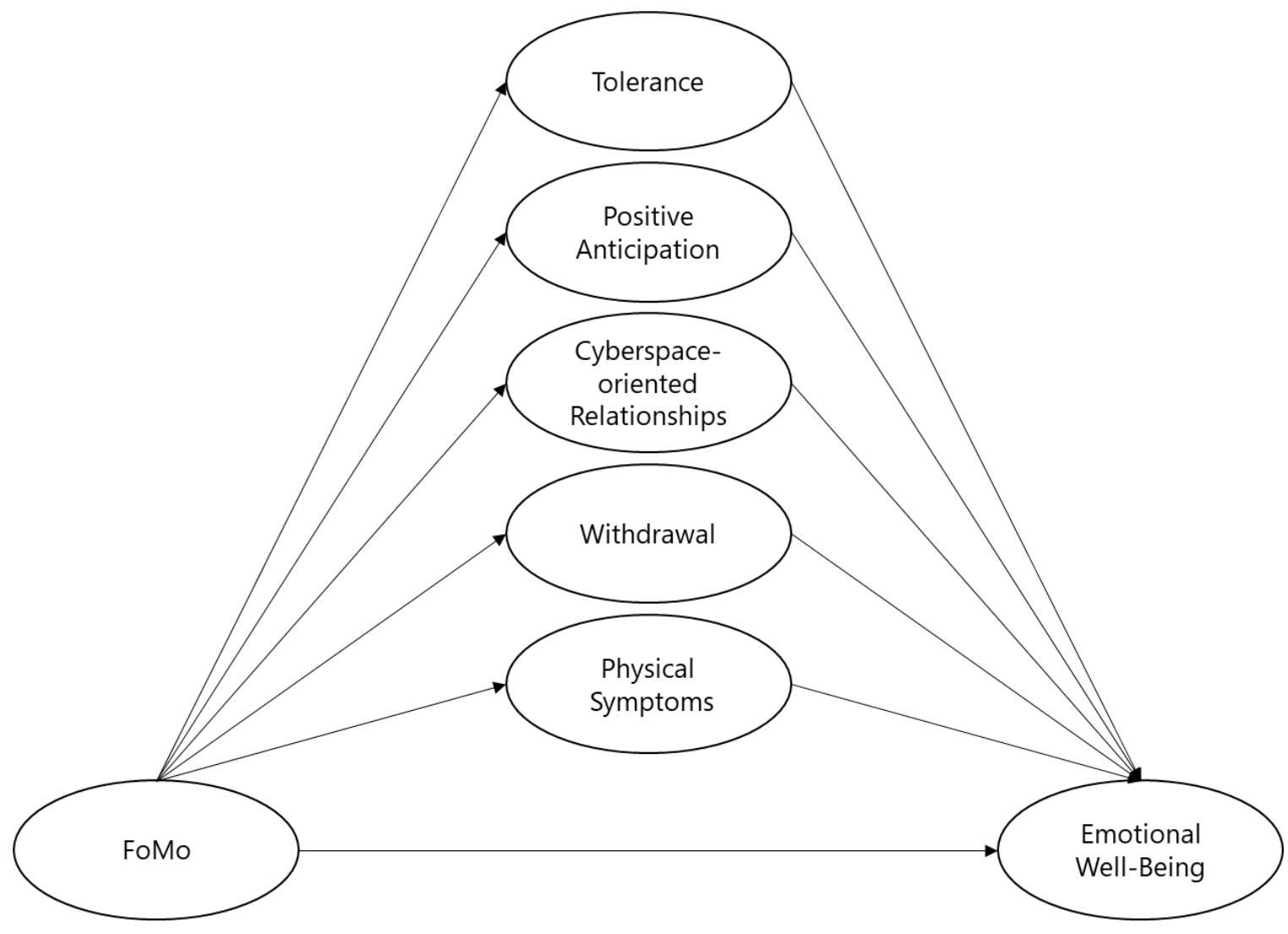

\section{Method}

\section{Participants}

Our aim was to reach at least 300 participants as this number is common in research on PSU (Elhai, Vasquez, et al., 2018; Rozgonjuk, Kattago, et al., 2018; Rozgonjuk, Levine, et al., 2018; Rozgonjuk, Saal, et al., 2018; Wolniewicz et al., 2020) and ensures that our study has sufficient statistical power to detect small $(r=.20)$ as well as larger effects (Cohen, 1988). Eventually, a sample of 426 Estonian participants volunteered and filled out the questionnaires. Most participants were female $(77 \%)$. Age ranged from 18 to 56 years $\left(M_{\text {age }}=26.74, S D=8.16\right)$. The majority of participants (93\%) indicated Estonian as their native language, while $7 \%$ selected "other language". The majority of participants (47.7\%) were student, $25.8 \%$ was employed and $26.3 \%$ were student and employed; one person $(0,2 \%)$ did not to respond to this question. Finally, $52.5 \%$ of the participants held a high school diploma, $5.2 \%$ held an applied higher education diploma, 21.9\% had obtained an undergraduate degree, $16.2 \%$ a master degree, and $4.2 \%$ a doctoral degree.

\section{Procedure}

We used convenience sampling technique to recruit the participants. Questionnaires were distributed online among Estonian employees and university students and included bachelor, master and doctoral students from a wide range of disciplines. They were contacted through the universities' mailing lists or through Facebook and were asked to fill out a series of questionnaires online. The survey period lasted from January 2018 to March 2018. Participants took part in the study on a voluntary basis and completed the questionnaires at home. All questionnaires were in the Estonian language. Participants completed the informed consent form online and were guaranteed permission to withdraw from the study at any time. To ensure anonymity, we replaced the emails of participants with a pseudo-identifier (code consisting of randomly generated characters). Moreover, all procedures were in compliance with the Declaration of Helsinki (World Medical Association, 2013) which outlines ethical principles and serves as a guideline for conducting research with human subjects. 


\section{Measures}

\section{Demographic Questions}

The demographic questionnaire consisted of five questions assessing gender, age, highest attained level of education (secondary, professional, applied higher education, bachelor, master, doctoral levels), main occupational status (employed, unemployed, student, employed/student), and native language (Estonian/Other).

\section{The Estonian Smartphone Addiction Proneness Scale}

The Estonian Smartphone Addiction Proneness Scale, E-SAPS18 (Rozgonjuk et al., 2016) is based on the Smartphone Addiction Scale (SAS) by Kwon and colleagues (Kwon et al., 2013) and consists of 18 items. It can be used either as a unidimensional or a multidimensional scale and has been demonstrated to have sound psychometric properties (see table 1 for the dimensions, items, and Cronbach's alphas from the original study of E-SAPS 18).

Table 1. Dimensions, Items and Cronbach's Alphas From the Original Study of E-SAPS 18.

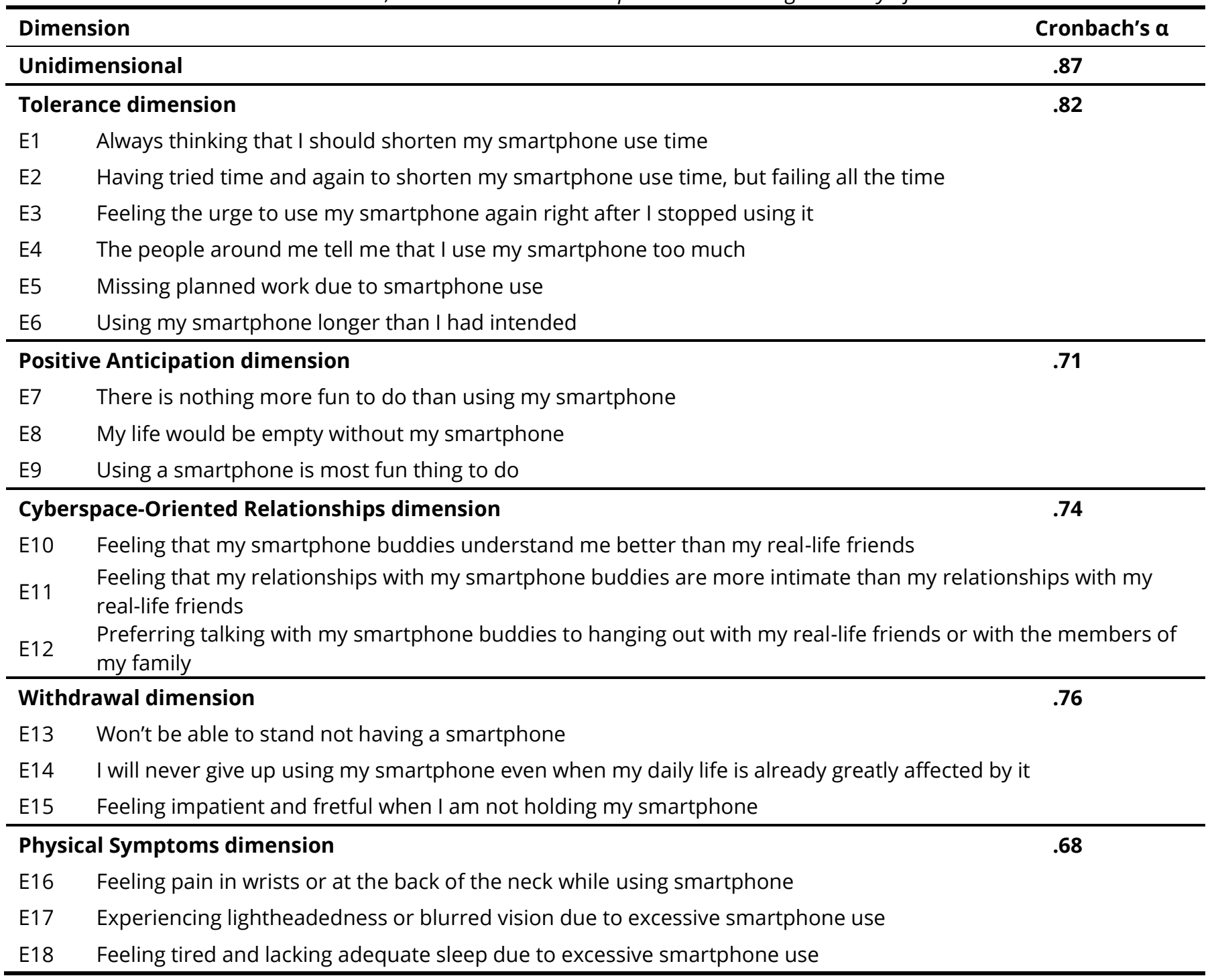

When used as a multidimensional scale it encompasses five different dimensions of problematic smartphone usage: (a) Tolerance - referring to the inability to control smartphone usage ( 6 items, including "Having tried time and again to shorten my smartphone use time, but failing all the time"); (b) Positive Anticipation - referring to feelings of excitement when using a smartphone and feelings of emptiness when not being able to do so ( 3 items, including "There is nothing more fun to do than using my smartphone"); (c) Cyberspace-oriented Relationships referring to a preference for online communication over face-to-face interactions ( 3 items, including "Feeling that my smartphone buddies understand me better than my real life friends"); (d) Withdrawal - referring to states of 
impatience, intolerance and irritation that arise due to the inability to use a smartphone or when one is being interrupted while using a smartphone ( 3 items, including "Feeling impatient and fretful when I am not holding my smartphone"); and (e) Physical Symptoms - referring to smartphone related physical complaints such as pain in the wrists, neck, blurred vision, and disturbed sleep ( 3 items, including "Feeling tired and lacking adequate sleep due to excessive smartphone use"). The names of the dimensions are mainly based on the Smartphone Addiction Scale - SAS (Kwon et al., 2013).

All items were rated on a six-point Likert scale, ranging from 0 (Strongly Disagree) to 5 (Strongly Agree). Participants were instructed to indicate to what extent these statements currently apply to them. Cronbach's alpha for PSU as a unidimensional construct for the present study is equal to .89. Cronbach's alpha's for PSU as a multidimensional construct for the present study: Tolerance (.87); Positive Anticipation (.69); Cyberspace-oriented Relationships (.75); Withdrawal (.76); Physical Symptoms (.69).

\section{The Fear of Missing Out (FoMO) Questionnaire}

The measure of FoMO is unidimensional and includes ten items. Example items are: "I get worried when I find out my friends are having fun without me" and "I fear others have more rewarding experiences than me". Respondents rate items on a five-point Likert scale, from 0 (not at all true of me) to 4 (extremely true of me). Participants were instructed to answer to what extent the statements generally apply to them. Cronbach's alpha for this measure in the present study is equal to .78. In order to translate and validate this scale in Estonian, the following steps were taken. First, forward and back-translation procedures were applied. Second, to validate the translation, a native speaker compared the original scale with the translated version and checked for possible incongruencies. Third, the final version of the Estonian FoMO questionnaire was tested for test-retest reliability and was administered twice $(n=178)$. The one-month test-retest reliability in the original study reached .77 and Cronbach's alpha was .79 (Raudlam, 2018).

\section{Emotional Well-Being Questionnaire}

Emotional well-being was measured by the Emotional State Questionnaire (Aluoja et al., 1999; Ööpik et al., 2006) which assesses the experience of a range of negative emotional states including depressive mood, anxiety, social anxiety, panic, and fatigue. This scale was developed by Estonian researchers (Aluoja et al., 1999), is widely used in Estonia (Dobewall et al., 2018; Kaare et al., 2009; Karelson et al., 2013), and has been shown to have sound psychometric properties with Cronbach's alpha of .88 (Aluoja et al., 1999).

Participants were instructed to rate the intensity and frequency of disturbing experiences during the last month, such as "tension, or inability to relax", "sadness", "feeling of anxiety and fear", on a five-point scale, from 0 (not at all) to 4 (constantly). We reversed the scores on this scale such that higher scores reflect higher levels of emotional well-being and the absence of mood related problems. Cronbach's alpha for this scale in the present study is .94.

\section{Data Analysis}

RStudio version 3.2.3 was used for analyzing the data. First, we calculated basic descriptive statistics for the assessed constructs. We applied Spearman's rank order correlation to compute bivariate relationships between the variables, as the items of PSU, FoMO and emotional well-being were not distributed normally and were positively skewed (see Table 2 for Skewness and Kurtosis values).

Next, we examined the factorial structure of the assessed variables. For this purpose, we conducted a confirmatory factor analysis using the R package Lavaan (Rosseel, 2012). We applied Diagonally Weighted Least Squares estimation (DWLS), because it has been shown to be less biased and more accurate than similar estimation methods (e.g., robust maximum likelihood, or MLR) for the ordinary data type (Mîndrilă, 2010). Goodness of fit was judged by standard parameters: (a) Comparative Fit Index (CFI), (b) Tucker-Lewis Index (TLI), (c) root mean square error of approximation (RMSEA), d) Standardized Root Mean Square Residual (SRMR), and e) Chi-square test. The following cutoff values were used to assess the goodness of fit of the models: higher than .90 for TLI, higher than .95 for CFI, .06 or less for RMSEA, and .08 or less for SRMR (Brown, 2006; Hooper et al., 2008; Hu \& Bentler, 1999; Schreiber et al., 2006). 
Next, to test our hypotheses we ran simple and parallel mediation analyses using the R package Lavaan (Rosseel, 2012), where (a) the latent score of FoMO was supposed to predict the latent score of (subdimensions of) PSU (H1), (b) the latent score of FoMO was supposed to predict the latent score of emotional well-being (H2), (c) the latent score of (subdimensions of) PSU were supposed to predict the latent score of emotional well-being (H3), and (d) the latent score of (subdimensions of) PSU were supposed to mediate the relation between the latent score of FoMO and the latent score of emotional well-being (H4). We used bootstrapping technique across 1000 samples and applied the abovementioned standard indices and cutoff scores to judge the goodness of fit of the models.

\section{Results}

Table 2. Descriptive Statistics and Correlations Between Averaged Scores of PSU (Unidimensional), Dimensions of PSU, FoMO and Emotional Well-Being.

\begin{tabular}{|c|c|c|c|c|c|c|c|c|c|c|c|c|}
\hline & & Mean & SD & Skewness & Kurtosis & 2 & 3 & 4 & 5 & 6 & 7 & 8 \\
\hline 1. & $\begin{array}{l}\text { PSU: Problematic } \\
\text { Smartphone use }\end{array}$ & 1.03 & 0.62 & 0.49 & -0.21 & .92 & .79 & .72 & .87 & .85 & .42 & -.47 \\
\hline 2. & PSU: Tolerance & 1.79 & 1.04 & 0.38 & -0.55 & & .59 & .48 & .40 & .77 & .34 & -.39 \\
\hline 3. & PSU: Positive Anticipation & 0.47 & 0.63 & 1.72 & 3.18 & & & .82 & .85 & .63 & .35 & -.36 \\
\hline 4. & $\begin{array}{l}\text { PSU: Cyberspace-oriented } \\
\text { Relationships }\end{array}$ & 0.58 & 0.74 & 1.42 & 1.96 & & & & .74 & .57 & .38 & -.42 \\
\hline 5. & PSU: Withdrawal & 1.33 & 0.96 & 0.57 & -0.08 & & & & & .65 & .36 & -.39 \\
\hline 6. & PSU: Physical Symptoms & 1.00 & 0.92 & 0.82 & -0.04 & & & & & & .39 & -.46 \\
\hline 7. & Fear of Missing out & 1.28 & 0.6 & 0.75 & 0.12 & & & & & & & -.42 \\
\hline 8. & Emotional Well-Being & 2.84 & 0.65 & -0.77 & 0.60 & & & & & & & \\
\hline
\end{tabular}

Note. All correlations are significant at $p<.001$ level.

The descriptive statistics for the assessed variables are presented in Table 2. We found that all dimensions of PSU were significantly associated with both FoMO and emotional well-being. The effect size of these associations is medium (Cohen, 1988).

\section{The Structure of FoMO, PSU, and Emotional Well-Being}

Before testing our hypotheses, we tested the measurement models of FoMO, PSU and emotional well-being to examine whether items loaded on their respective scales. For this purpose, we ran a series of confirmatory factor analyses (see Table 3 for fit indices of all measurement models).

Table 3. Fit Indices of Measurement Models for FoMO, PSU, Five-Dimensional PSU and Emotional Well-Being.

\begin{tabular}{|c|c|c|c|c|c|c|c|c|c|c|}
\hline \multirow{2}{*}{\multicolumn{2}{|c|}{ Model }} & \multirow{3}{*}{$\begin{array}{l}\text { Dimensions } \\
\text { One }\end{array}$} & \multirow{2}{*}{$\chi^{2}$} & \multirow{2}{*}{$p$} & \multirow{2}{*}{ SRMR } & \multirow{2}{*}{ TLI } & \multirow{2}{*}{$\mathrm{CFI}$} & \multirow{2}{*}{ RMSEA } & \multicolumn{2}{|c|}{$90 \% \mathrm{Cl}$} \\
\hline & & & & & & & & & $\mathrm{LL}$ & UL \\
\hline 1 & FoMO & & $80.437(34)$ & $<.001$ & .065 & .95 & .96 & .058 & .042 & .075 \\
\hline \multirow{2}{*}{2} & \multirow{2}{*}{ PSU } & One & $338.47(104)$ & $<.001$ & .061 & .98 & .99 & .04 & .03 & .05 \\
\hline & & Five & $118.36(109)$ & .25 & .049 & .99 & .99 & .015 & .00 & .03 \\
\hline 3 & EWB & One & $532.528(350)$ & $<.001$ & .072 & .99 & .99 & .036 & .030 & .042 \\
\hline
\end{tabular}

Note. $\mathrm{PSU}=$ Problematic smartphone use; EWB = Emotional well-being; Cl = confidence interval; LL = lower limit; UL = upper limit.

First, we examined the structure of the FoMO questionnaire. Specifically, we built a model where FoMO was considered as a latent variable and 10 items as observed variables. This model, however, did not show adequate fit. The modification indices indicated that the first two items of the scale: "I fear that my friends have more rewarding experiences in their lives than me" and "I fear others are having more rewarding experiences than me" were highly correlated with each other. Therefore, we allowed an inter-correlation between these two items which improved the goodness of fit of the model (see top Table 3). It is notable that removing one of the two items 
(rather than allowing for an inter-correlation) led to the same results and does not modify any conclusion reported in the paper.

Second, we investigated the factorial structure of PSU. One item ("There is nothing more fun to do than using my smartphone") hardly showed any variance and this item was therefore excluded from all further analyses. We examined the fit of a five-dimension model where all items loaded on their respective scale, as well as a unidimensional model where the five factors loaded on one higher order factor. Both models fitted our data very well (see the middle section of Table 3), and is consistent with the five-dimensional structure of the PSU scale obtained in an earlier study in an Estonian sample (Rozgonjuk et al., 2016).

Finally, we examined the structure of the emotional well-being scale, where all items were expected to load on one latent variable. The model demonstrated also a good fit (see bottom Table 3).

\section{The Relation Between FoMO, PSU, and Emotional Well-Being}

To test our hypotheses and answer our research question, we ran two mediation analyses. First, we built a structural model where PSU was treated as a one-dimensional construct supposed to mediate the relation between FoMO and emotional well-being (see Figure 3). We added gender to the model to control for its effect on emotional well-being. We used a bootstrapping procedure across 1000 samples to test the indirect effects. Fit indices of the mediation model were very good: $\mathrm{CFI}=.98$ and TLI $=.98, \mathrm{SRMR}=.066, \mathrm{RMSEA}=.036,90 \% \mathrm{Cl}[.032$, .039]. FoMO significantly predicted PSU, $B=0.625, \beta=.616, S E=.110, p<.001$. Further, FoMO significantly predicted diminished emotional well-being $B=-0.492, \beta=-.455, S E=.076, p<.001$. PSU also significantly predicted decreased emotional well-being $B=-0.317$, $\beta=-.298, S E=.086, p<.001$. Finally, PSU accounted for the association between FoMO and emotional well-being, when controlling for gender. The indirect effect of FoMO on emotional well-being through PSU was significant $B=$ $-0.198 ; \beta=-.183, S E=.056, p=.001$. The direct path $\left(c^{\prime}\right)$ from FoMO to diminished emotional well-being also remained significant, reflecting a partial mediation effect $B=-0.492, \beta=-.455, S E=.076, p=.001$.

Figure 3. PSU (Unidimensional) as a Significant Mediator of the Relationship Between FoMO and Emotional Well-Being (Controlling for Gender).

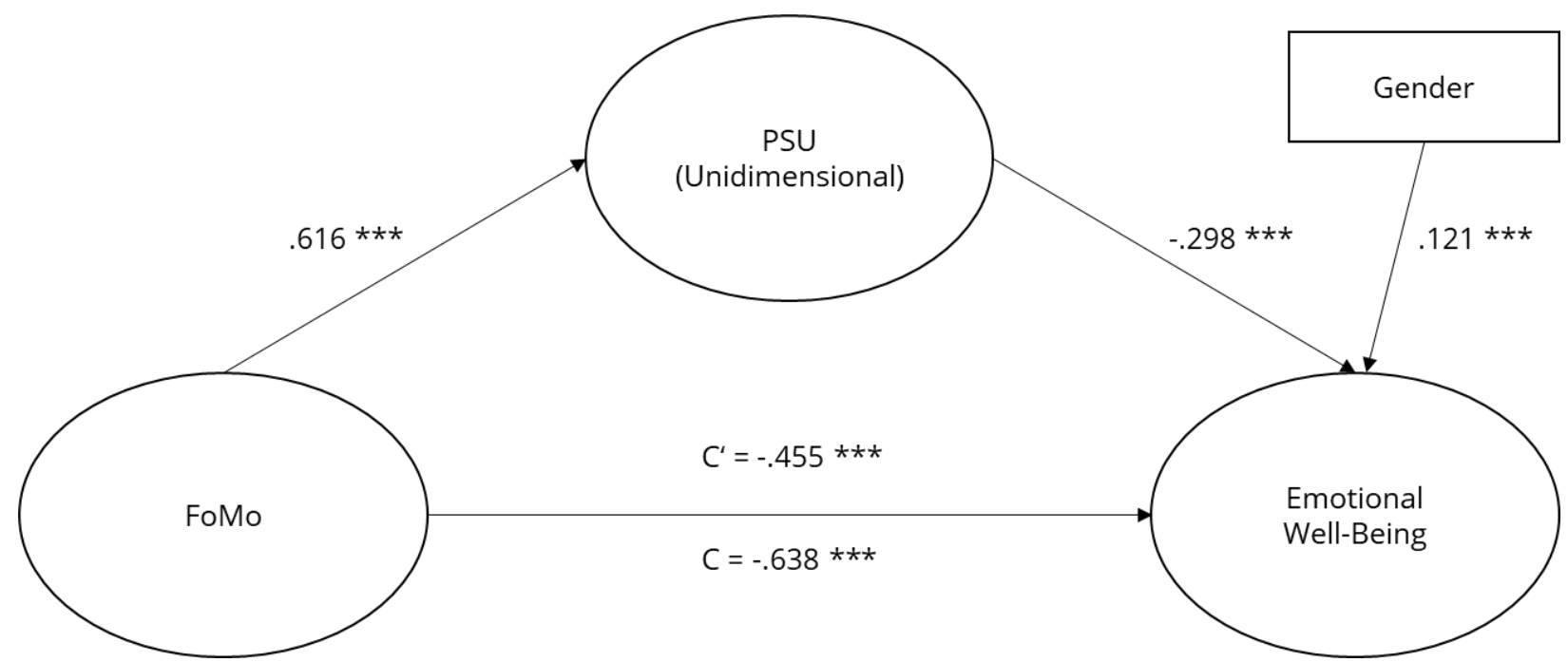

Note. Regression weights are standardized. $C^{\prime}$ is the direct effect of FoMO on emotional well-being; $C$ is the total effect of FoMO on emotional well-being.

Next, we fitted a model where the five dimensions of PSU mediated the relationship between FoMO and emotional well-being (see Figure 4). We used again a bootstrapping procedure across 1000 samples to test the indirect effects. Gender was added in the model to control for its effect on emotional well-being. Fit indices of the model were good: $\mathrm{CFI}=.98$ and $\mathrm{TLI}=.98, \mathrm{SRMR}=.068, \mathrm{RMSEA}=.038,90 \% \mathrm{Cl}[.034, .042]$. The relationship between FoMO 
and emotional well-being was mediated by two dimensions of PSU: Cyberspace-oriented Relationships and Physical Symptoms. Other paths in this structural model were statistically non-significant (see Figure 4 and Table 4).

Figure 4. PSU (Multidimensional: All Five Dimensions) as a Mediator of the Relationship Between FoMO and Emotional Well-Being (After Controlling for Gender).

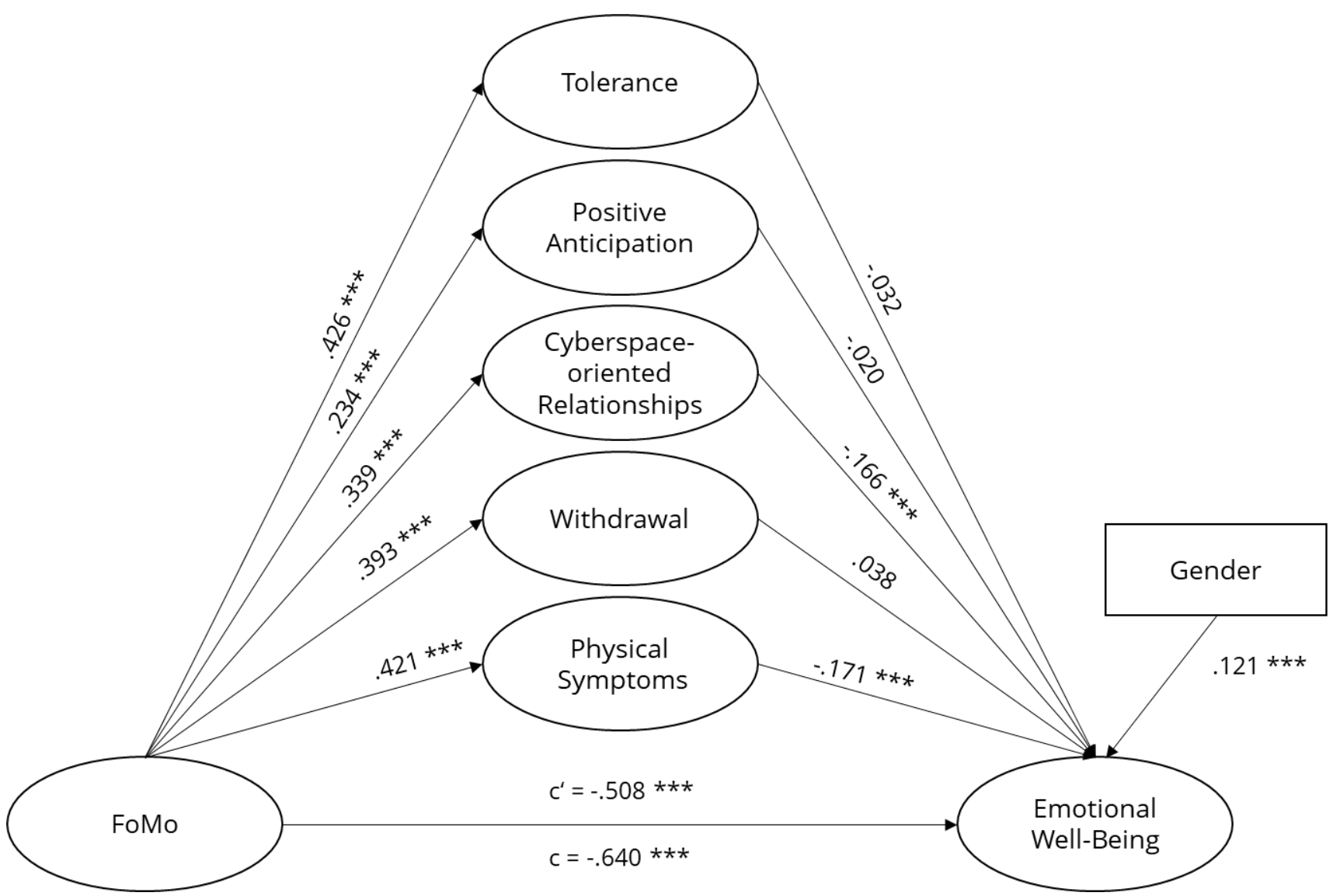

Note. Regression weights are standardized. $C$ is the direct effect of FoMO on emotional well-being; $C$ is the total effect of FoMO on emotional well-being.

Table 4. Direct and Indirect Effects of FoMO on Emotional Well-Being (WB).

\begin{tabular}{lcccc}
\hline Mediating Relationships & $\beta$ & $B$ & $S E$ & $p$ \\
\hline Total effect & -.640 & -0.670 & .066 & .000 \\
Direct effect & -.508 & -0.532 & .066 & .000 \\
FoMO->Tolerance->WB & -.014 & -0.014 & .024 & .556 \\
FoMO->Positive Anticipation->WB & -.005 & -0.005 & .013 & .699 \\
FoMO->Cyberspace-oriented Relationships ->WB & -.056 & -0.059 & .021 & .005 \\
FoMO->Withdrawal->WB & -.015 & -0.015 & .023 & .497 \\
FoMO->Physical Symptoms->WB & -.072 & -0.075 & .026 & .003 \\
\hline
\end{tabular}

A final structural model including only the two significant mediating PSU dimensions met the cutoff criteria for good fit: $\mathrm{CFI}=.98$ and $\mathrm{TLI}=.98, \mathrm{SRMR}=.062$, RMSEA $=.038,90 \% \mathrm{Cl}[.034, .042]$. Both Cyberspace-oriented Relationships and Physical Symptoms were positively predicted by FoMO. In their turn, both dimensions predicted diminished emotional well-being. The indirect effect for Cyberspace-oriented Relationships was $B=-0.059, \beta=-$ $.056, S E=.021, p=.005$ and for Physical Symptoms $B=-0.075, \beta=-.072, S E=.026, p=.003$. Moreover, the direct effect of FoMO on emotional well-being became smaller but remained significant $B=-0.532, \beta=-.508, S E=.066, p$ $<.001$, reflecting a partial mediation effect. 


\section{Discussion}

The aim of the present study was to investigate whether (subdimensions of) PSU mediate the relationship between FoMO and emotional well-being among an Estonian sample. In the first set of analyses, we examined PSU as a one-dimensional construct. We found that FoMO predicted PSU and diminished emotional well-being. Moreover, PSU predicted decreased emotional well-being. Most importantly, PSU partially mediated the relation between FoMO and decreased emotional well-being.

At an empirical level, these findings are related to previous evidence showing that FoMO predicts overuse of social network sites (Franchina et al., 2018), which in turn predicts decreased well-being (Dhir et al., 2018). However, our results add to this research by showing that the mediating pathway might go beyond social network sites and extends to problematic smartphone use as well.

At a theoretical level, our findings lend support to the I-PACE model, which posits that various psychological factors, including person-level characteristics, such as FoMO, eventually drive individuals to overuse their smartphones (Brand et al., 2019). As smartphones give individuals unlimited online access to check what others are doing, excessive use of these devices can be seen as a maladaptive coping strategy or an end product of frequent, habitual checking to alleviate excessive worry arising from FoMO. According to the I-PACE model, such overuse would not help to cope with these worries but result in adverse outcomes. This claim is confirmed by the present study, showing the detrimental impact of smartphone overuse on emotional well-being.

In the second set of analyses, we examined PSU as a multidimensional construct. We found that two dimensions of PSU partially mediated the relation between FoMO and decreased emotional well-being: Cyberspace-oriented Relationships and Physical Symptoms. While FoMO predicted all dimensions of PSU, only the dimensions Cyberspace-oriented Relationships and Physical Symptoms predicted in turn diminished well-being. This indicates that not all dimensions of PSU are equally harmful to emotional well-being.

Why would those two dimensions negatively impact emotional well-being? The negative relation between the dimension Physical Symptoms and decreased emotional well-being is consistent with the broader literature on the connection between Physical Symptoms and decreased subjective well-being (Diener et al., 2017). Constant checking of one's smartphone may cause physical symptoms such as blurred vision or pain in the wrists, which then can lead to decreased levels of emotional well-being.

The negative impact of Cyberspace-oriented Relationships (i.e., preference for online friendship over real-life friendship) can be connected to the displacement hypothesis (Kraut et al., 1998). According to this hypothesis usage of online technologies displaces face-to-face interactions (Franchina et al., 2018; Guo et al., 2019; Lepp et al., 2016; Nie, 2001). Face-to-face interactions with family and friends have repeatedly been shown to be positive predictors of subjective well-being (Caunt et al., 2013; Diener \& Seligman, 2002; Kross et al., 2013; Rotondi et al., 2017). The lack of face-to-face interactions following FoMO may then explain the negative impact of FoMO on emotional well-being. It is noteworthy that earlier findings regarding the consequences of the Cyberspaceoriented Relationships dimension are inconclusive. According to a study by S. Lee and colleagues (2018), this dimension reflects a healthy aspect of smartphone use and is positively associated with interpersonal competence. In contrast, a study by Darcin and colleagues (2015) reported that the Cyberspace-oriented Relationship dimension was positively associated with loneliness. Our findings are more consistent with the latter study.

\section{Theoretical and Practical Implications}

Our findings have a number of implications at a theoretical and practical level. With regard to theoretical implications, the present study is the first to explicitly focus and investigate in detail the relation between FoMO, dimensions of PSU, and emotional well-being. In doing so, we have demonstrated that only the dimensions of Cyberspace-oriented Relationships and Physical Symptoms partially mediate the connection between FoMO and emotional well-being. As such, instead of focusing on PSU as a unidimensional construct, researchers might find value in paying attention to subdimensions of PSU. It is notable that by focusing on negative indicators of emotional well-being, we have shown that FoMO indirectly increases negative mood through (subdimensions of) 
PSU. Considering that negative emotions tend to last longer, have stronger effects and require more cognitive involvement than positive emotions (Larsen, 2009), these findings further advance our understanding of the detrimental impact of FoMO and PSU. Nevertheless, future research focusing on the experience of positive emotions are needed to further deepen our understanding of the impact of FoMO and PSU on emotional wellbeing.

With regard to practical implications, counselors could use this information when evaluating problematic smartphone usage patterns of their clients or when designing interventions to help clients' with high levels of FoMO. For instance, when noticing in clients that their FoMO results in a strong preference for online connections, counselors may stimulate their clients to engage more in face-to-face interactions. Since children and youth are ardent users of technology in general, and smartphones in particular (Orben, 2020) also parents could benefit from the present evidence. Specifically, parents could use the present evidence when setting rules for healthy usage of smartphones. Finally, in conjunction with other findings, our results can be used by policy-makers for evidence-based decision making.

\section{Limitations and Future Research}

Like all studies, the present study has a number of limitations. First, due to the cross-sectional design, causal interpretations should be made with caution. Even though we constructed and tested a model where PSU mediates the relation between FoMO and emotional well-being, alternative models are also possible. Future studies using experimental and longitudinal designs are needed to further examine the temporal relation between these variables.

Second, PSU only partially mediated the relationship between FoMO and emotional well-being. This implies that additional mediating mechanisms may play a role which could be examined in future studies.

Third, we used a university student sample that consisted of mainly female participants. Considering the findings that females and males use smartphones differently (Andone et al., 2016) and that females are more prone to smartphone addiction (Choi et al., 2015), future studies may recruit more heterogeneous samples in terms of gender and explore its possibly moderating effect.

\section{Conclusion}

In this study, we investigated the relation between FoMO, PSU, and emotional well-being. We found that PSU partially mediated the relationship between FoMO and decreased emotional well-being. Treating PSU as a multidimensional construct, we specifically found that two specific dimensions of PSU were significant mediators: Cyberspace-oriented Relationships and Physical Symptoms. This suggests that the negative relationship between FoMO and emotional well-being is due to FoMO stimulating (a) online relationships at the cost of offline interactions and (b) Physical symptoms associated with excessive smartphone use.

\section{References}

Adelhardt, Z., Markus, S., \& Eberle, T. (2018). Teenagers' reaction on the long-lasting separation from smartphones, anxiety and fear of missing out. In SMSociety '18: Proceedings of the 9th International Conference on Social Media and Society (pp. 212-216). ACM. https://doi.org/10.1145/3217804.3217914

Alt, D. (2015). College students' academic motivation, media engagement and fear of missing out. Computers in Human Behavior, 49, 111-119. https://doi.org/10.1016/j.chb.2015.02.057

Aluoja, A., Shlik, J., Vasar, V., Luuk, K., \& Leinsalu, M. (1999). Development and psychometric properties of the Emotional State Questionnaire, a self-report questionnaire for depression and anxiety. Nordic Journal of Psychiatry, 53(6), 443-449. https://doi.org/10.1080/080394899427692 
Andone, I., Błaszkiewicz, K., Eibes, M., Trendafilov, B., Markowetz, A., \& Montag, C. (2016). How age and gender affect smartphone usage. In UbiComp '16: Proceedings of the 2016 ACM International Joint Conference on Pervasive and Ubiquitous Computing: Adjunct (pp. 9-12). ACM. https://doi.org/10.1145/2968219.2971451

Ashton, J. J., \& Beattie, R. M. (2019). Screen time in children and adolescents: Is there evidence to guide parents and policy? The Lancet Child \& Adolescent Health, 3(5), 292-294. https://doi.org/10.1016/S2352-4642(19)30062-8

Augner, C., \& Hacker, G. W. (2012). Associations between problematic mobile phone use and psychological parameters in young adults. International Journal of Public Health, 57(2), 437-441. https://doi.org/10.1007/s00038011-0234-z

Baker, Z. G., Krieger, H., \& LeRoy, A. S. (2016). Fear of missing out: Relationships with depression, mindfulness, and physical symptoms. Translational Issues in Psychological Science, 2(3), 275-282.

https://doi.org/10.1037/tps0000075

Barkan, R. (2019, December 23). The smartphone is our era's cigarette - and just as hard to quit. The Guardian. https://www.theguardian.com/commentisfree/2019/dec/23/smartphone-techology-iphone-mobile-cigarettes

Barker, E. (2016, June 7). This is the best way to overcome fear of missing out. Time.

https://time.com/4358140/overcome-fomo/

Billieux, J., Maurage, P., Lopez-Fernandez, O., Kuss, D. J., \& Griffiths, M. D. (2015). Can disordered mobile phone use be considered a behavioral sddiction? An update on current evidence and a comprehensive model for future research. Current Addiction Reports, 2(2), 156-162. https://doi.org/10.1007/s40429-015-0054-y

Billieux, J., Philippot, P., Schmid, C., Maurage, P., De Mol, J., \& Van der Linden, M. (2015). Is dysfunctional use of the mobile phone a behavioural addiction? Confronting symptom-based versus process-based approaches. Clinical Psychology \& Psychotherapy, 22(5), 460-468. https://doi.org/10.1002/cpp.1910

Błachnio, A., \& Przepiórka, A. (2018). Facebook intrusion, fear of missing out, narcissism, and life satisfaction: A cross-sectional study. Psychiatry Research, 259, 514-519. https://doi.org/10.1016/j.psychres.2017.11.012

Blackwell, D., Leaman, C., Tramposch, R., Osborne, C., \& Liss, M. (2017). Extraversion, neuroticism, attachment style and fear of missing out as predictors of social media use and addiction. Personality and Individual Differences, 116, 69-72. https://doi.org/10.1016/j.paid.2017.04.039

Brand, M., Wegmann, E., Stark, R., Müller, A., Wölfling, K., Robbins, T. W., \& Potenza, M. N. (2019). The Interaction of Person-Affect-Cognition-Execution (I-PACE) model for addictive behaviors: Update, generalization to addictive behaviors beyond internet-use disorders, and specification of the process character of addictive behaviors. Neuroscience \& Biobehavioral Reviews, 104, 1-10. https://doi.org/10.1016/j.neubiorev.2019.06.032

Brand, M., Young, K. S., Laier, C., Wölfling, K., \& Potenza, M. N. (2016). Integrating psychological and neurobiological considerations regarding the development and maintenance of specific Internet-use disorders: An Interaction of Person-Affect-Cognition-Execution (I-PACE) model. Neuroscience \& Biobehavioral Reviews, 71, 252-266. https://doi.org/10.1016/j.neubiorev.2016.08.033

Brown, T. A. (2006). Confirmatory factor analysis for applied research. Guilford Press.

Browne, B. L., Aruguete, M. S., McCutcheon Lynn E, \& Medina, A. M. (2018). Social and emotional correlates of the fear of missing out. North American Journal of Psychology, 20(3), 341-354.

Brueck, H., \& Lee, S. (2018, March 24). Why our phones are making us miserable: Happiness isn't the same thing as pleasure, and our brain knows it. Business Insider. https://www.businessinsider.com/why-our-phones-aremaking-us-miserable-pleasure-isnt-happiness-2018-3?international=true\&r=US\&IR=T 
Burnell, K., George, M. J., Vollet, J. W., Ehrenreich, S. E., \& Underwood, M. K. (2019). Passive social networking site use and well-being: The mediating roles of social comparison and the fear of missing out. Cyberpsychology: Journal of Psychosocial Research on Cyberspace, 13(3), Article 5. https://doi.org/10.5817/cp2019-3-5

Camacho, E., LoPresti, M., Appelboom, G., Dumont, E. L. P., Taylor, B., \& Connoly, E. S. (2014). The ubiquitous role of smartphones in mobile health. Biometrics \& Biostatistics International Journal, 1(1), 14-19.

https://doi.org/10.15406/bbij.2014.01.00004

Canadian Paediatric Society, Digital Health Task Force. (2017). Screen time and young children: Promoting health and development in a digital world. Paediatrics \& Child Health, 22(8), 461-468. https://doi.org/10.1093/pch/pxx123

Caunt, B. S., Franklin, J., Brodaty, N. E., \& Brodaty, H. (2013). Exploring the causes of subjective well-being: A content analysis of peoples' recipes for long-term happiness. Journal of Happiness Studies, 14(2), 475-499. https://doi.org/10.1007/s10902-012-9339-1

Chan, M. (2015). Mobile phones and the good life: Examining the relationships among mobile use, social capital and subjective well-being. New Media \& Society, 17(1), 96-113. https://doi.org/10.1177/1461444813516836

Chassiakos, Y. R., Radesky, J., Christakis, D., Moreno, M. A., Cross, C., \& Council on Communications and Media. (2016). Children and adolescents and digital media. Pediatrics, 138(5), Article e20162593.

https://doi.org/10.1542/peds.2016-2593

Chen, J., Liang, Y., Mai, C., Zhong, X., \& Qu, C. (2016). General deficit in inhibitory control of excessive smartphone users: Evidence from an event-related potential study. Frontiers in Psychology, 7, Article 511.

https://doi.org/10.3389/fpsyg.2016.00511

Ching, S. M., Yee, A., Ramachandran, V., Lim, S. M. S., Sulaiman, W. A. W., Foo, Y. L., \& Hoo, F. K. (2015). Validation of a Malay version of the Smartphone Addiction Scale among medical students in Malaysia. PLOS ONE, 10(10), Article e0139337. https://doi.org/10.1371/journal.pone.0139337

Choi, S.-W., Kim, D.-J., Choi, J.-S., Ahn, H., Choi, E.-J., Song, W.-Y., Kim, S., \& Youn, H. (2015). Comparison of risk and protective factors associated with smartphone addiction and Internet addiction. Journal of Behavioral Addictions, 4(4), 308-314. https://doi.org/10.1556/2006.4.2015.043

Chotpitayasunondh, V., \& Douglas, K. M. (2016). How "phubbing" becomes the norm: The antecedents and consequences of snubbing via smartphone. Computers in Human Behavior, 63, 9-18.

https://doi.org/10.1016/j.chb.2016.05.018

Cohen, J. (1988). Statistical power analysis for the behavioral sciences (2nd ed.). Routledge. https://doi.org/10.4324/9780203771587

ComScore. (2017, March 31). Mobile matures as the cross-platform era emerges.

https://www.comscore.com/Insights/Blog/Mobile-Matures-as-the-Cross-Platform-Era-Emerges

Contractor, A. A., Weiss, N. H., Tull, M. T., \& Elhai, J. D. (2017). PTSD's relation with problematic smartphone use: Mediating role of impulsivity. Computers in Human Behavior, 75, 177-183.

https://doi.org/10.1016/j.chb.2017.05.018

Darcin, A. E., Noyan, C., Nurmedov, S., Yilmaz, O., \& Dilbaz, N. (2015). Smartphone addiction in relation with social anxiety and loneliness among university students in Turkey. European Psychiatry, 30(Suppl. 1), 505.

https://doi.org/10.1016/s0924-9338(15)30398-9

Davie, M., \& Firth, A. (2019). The health impacts of screen time: A guide for clinicians and parents. Royal College of Paediatrics and Child Health. https://www.rcpch.ac.uk/resources/health-impacts-screen-time-guide-cliniciansparents 
Demirci, K., Akgönül, M., \& Akpinar, A. (2015). Relationship of smartphone use severity with sleep quality, depression, and anxiety in university students. Journal of Behavioral Addictions, 4(2), 85-92.

https://doi.org/10.1556/2006.4.2015.010

Dhir, A., Yossatorn, Y., Kaur, P., \& Chen, S. (2018). Online social media fatigue and psychological wellbeing-A study of compulsive use, fear of missing out, fatigue, anxiety and depression. International Journal of Information Management, 40, 141-152. https://doi.org/10.1016/j.jinfomgt.2018.01.012

Diener, E., Pressman, S. D., Hunter, J., \& Delgadillo-Chase, D. (2017). If, why, and when subjective well-being influences health, and future needed research. Applied Psychology: Health and Well-Being, 9(2), 133-167.

https://doi.org/10.1111/aphw.12090

Diener, E., \& Seligman, M. E. P. (2002). Very happy people. Psychological Science, 13(1), 81-84.

https://doi.org/10.1111/1467-9280.00415

Ding, D., \& Li, J. (2017). Smartphone overuse - A growing public health issue. Journal of Psychology \& Psychotherapy, 7(1), Article 289. https://doi.org/10.4172/2161-0487.1000289

Dobewall, H., Tark, R., \& Aavik, T. (2018). Health as a value and its association with health-related quality of life, mental health, physical health, and subjective well-being. Applied Research in Quality of Life, 13(4), 859-872. https://doi.org/10.1007/s11482-017-9563-2

Duke, É., \& Montag, C. (2017). Smartphone addiction, daily interruptions and self-reported productivity. Addictive Behaviors Reports, 6, 90-95. https://doi.org/10.1016/j.abrep.2017.07.002

Eid, M., \& Larsen, R. J. (Eds.). (2008). The science of subjective well-being. Guilford Press.

Elhai, J. D., Dvorak, R. D., Levine, J. C., \& Hall, B. J. (2017). Problematic smartphone use: A conceptual overview and systematic review of relations with anxiety and depression psychopathology. Journal of Affective Disorders, 207, 251-259. https://doi.org/10.1016/j.jad.2016.08.030

Elhai, J. D., Hall, B. J., Levine, J. C., \& Dvorak, R. D. (2017). Types of smartphone usage and relations with problematic smartphone behaviors: The role of content consumption vs. social smartphone use. Cyberpsychology: Journal of Psychosocial Research on Cyberspace, 11(2), Article 3. https://doi.org/10.5817/CP2017-23

Elhai, J. D., Levine, J. C., Alghraibeh, A. M., Alafnan, A. A., Aldraiweesh, A. A., \& Hall, B. J. (2018). Fear of missing out: Testing relationships with negative affectivity, online social engagement, and problematic smartphone use. Computers in Human Behavior, 89, 289-298. https://doi.org/10.1016/j.chb.2018.08.020

Elhai, J. D., Levine, J. C., Dvorak, R. D., \& Hall, B. J. (2016). Fear of missing out, need for touch, anxiety and depression are related to problematic smartphone use. Computers in Human Behavior, 63, 509-516. https://doi.org/10.1016/j.chb.2016.05.079

Elhai, J. D., Levine, J. C., Dvorak, R. D., \& Hall, B. J. (2017). Non-social features of smartphone use are most related to depression, anxiety and problematic smartphone use. Computers in Human Behavior, 69, 75-82.

https://doi.org/10.1016/j.chb.2016.12.023

Elhai, J. D., Rozgonjuk, D., Liu, T., \& Yang, H. (2020). Fear of missing out predicts repeated measurements of greater negative affect using experience sampling methodology. Journal of Affective Disorders, 262, 298-303. https://doi.org/10.1016/j.jad.2019.11.026

Elhai, J. D., Rozgonjuk, D., Yildirim, C., Alghraibeh, A. M., \& Alafnan, A. A. (2019). Worry and anger are associated with latent classes of problematic smartphone use severity among college students. Journal of Affective Disorders, 246, 209-216. https://doi.org/10.1016/j.jad.2018.12.047 
Elhai, J. D., Tiamiyu, M., \& Weeks, J. (2018). Depression and social anxiety in relation to problematic smartphone use: The prominent role of rumination. Internet Research, 28(2), 315-332. https://doi.org/10.1108/intr-01-20170019

Elhai, J. D., Vasquez, J. K., Lustgarten, S. D., Levine, J. C., \& Hall, B. J. (2018). Proneness to boredom mediates relationships between problematic smartphone use with depression and anxiety severity. Social Science Computer Review, 36(6), 707-720. https://doi.org/10.1177/0894439317741087

Franchina, V., Vanden Abeele, M., Van Rooij, A. J., Lo Coco, G., \& De Marez, L. (2018). Fear of missing out as a predictor of problematic social media use and phubbing behavior among Flemish adolescents. International Journal of Environmental Research and Public Health, 15(10), Article 2319. https://doi.org/10.3390/ijerph15102319

Fredrickson, B. L., \& Joiner, T. (2002). Positive emotions trigger upward spirals toward emotional well-being. Psychological Science, 13(2), 172-175. https://doi.org/10.1111/1467-9280.00431

Godwin-Jones, R. (2011). Emerging technologies: Mobile apps for language learning. Language Learning \& Technology, 15(2), 2-11. http://dx.doi.org/10125/44244

Guo, N., Wang, M. P., Luk, T. T., Ho, S. Y., Fong, D. Y. T., Chan, S. S.-C., \& Lam, T. H. (2019). The association of problematic smartphone use with family well-being mediated by family communication in Chinese adults: A population-based study. Journal of Behavioral Addictions, 8(3), 412-419. https://doi.org/10.1556/2006.8.2019.39

Harwood, J., Dooley, J. J., Scott, A. J., \& Joiner, R. (2014). Constantly connected - The effects of smart-devices on mental health. Computers in Human Behavior, 34, 267-272. https://doi.org/10.1016/j.chb.2014.02.006

Heller, N. (2017, December 11). Estonia, the digital republic. The New Yorker.

https://www.newyorker.com/magazine/2017/12/18/estonia-the-digital-republic

Hooper, D., Coughlan, J., \& Mullen, M. R. (2008). Structural equation modelling: Guidelines for determining model fit. Electronic Journal of Business Research Methods, 6(1), 53-60.

Hu, L.-t., \& Bentler, P. M. (1999). Cutoff criteria for fit indexes in covariance structure analysis: Conventional criteria versus new alternatives. Structural Equation Modeling: A Multidisciplinary Journal, 6(1), 1-55.

https://doi.org/10.1080/10705519909540118

Hussain, Z., Griffiths, M. D., \& Sheffield, D. (2017). An investigation into problematic smartphone use: The role of narcissism, anxiety, and personality factors. Journal of Behavioral Addictions, 6(3), 378-386.

https://doi.org/10.1556/2006.6.2017.052

Inal, E. E., Demirci, K., Çetintürk, A., Akgönül, M., \& Savaş, S. (2015). Effects of smartphone overuse on hand function, pinch strength, and the median nerve. Muscle \& Nerve, 52(2), 183-188.

https://doi.org/10.1002/mus.24695

Kaare, P.-R., Mõttus, R., \& Konstabel, K. (2009). Pathological gambling in Estonia: Relationships with personality, self-esteem, emotional states and cognitive ability. Journal of Gambling Studies, 25(3), 377-390.

https://doi.org/10.1007/s10899-009-9119-y

Kahneman, D., \& Deaton, A. (2010). High income improves evaluation of life but not emotional well-being. PNAS, 107(38), 16489-16493. https://doi.org/10.1073/pnas.1011492107

Karelson, M., Silm, H., \& Kingo, K. (2013). Quality of life and emotional state in vitiligo in an Estonian sample: Comparison with psoriasis and healthy controls. Acta Dermato-Venereologica, 93(4), 446-450.

https://doi.org/10.2340/00015555-1520 
Kim, D., Lee, Y., Lee, J., Nam, J. E. K., \& Chung, Y. (2014). Development of Korean Smartphone Addiction Proneness Scale for youth. PLOS ONE, 9(5), Article e97920. https://doi.org/10.1371/journal.pone.0097920

Kim, H.-J., Min, J.-Y., Kim, H.-J., \& Min, K.-B. (2019). Association between psychological and self-assessed health status and smartphone overuse among Korean college students. Journal of Mental Health, 28(1), 11-16. https://doi.org/10.1080/09638237.2017.1370641

Kircaburun, K., Griffiths, M. D., Şahin, F., Bahtiyar, M., Atmaca, T., \& Tosuntaş, Ş. B. (2020). The mediating role of self/everyday creativity and depression on the relationship between creative personality traits and problematic social media use among emerging adults. International Journal of Mental Health and Addiction, 18(1), 77-88. https://doi.org/10.1007/s11469-018-9938-0

Kraut, R., Patterson, M., Lundmark, V., Kiesler, S., Mukopadhyay, T., \& Scherlis, W. (1998). Internet paradox: A social technology that reduces social involvement and psychological well-being? American Psychologist, 53(9), 1017-1031. https://doi.org/10.1037/0003-066X.53.9.1017

Kross, E., Verduyn, P., Demiralp, E., Park, J., Lee, D. S., Lin, N., Shablack, H., Jonides, J., \& Ybarra, O. (2013). Facebook use predicts declines in subjective well-being in young adults. PLOS ONE, 8(8), Article e69841. https://doi.org/10.1371/journal.pone.0069841

Kwon, M., Lee, J.-Y., Won, W.-Y., Park, J.-W., Min, J.-A., Hahn, C., Gu, X., Choi, J.-H., \& Kim, D.-J. (2013). Development and validation of a Smartphone Addiction Scale (SAS). PLOS ONE, 8(2), Article e56936.

https://doi.org/10.1371/journal.pone.0056936

Lai, C., Altavilla, D., Ronconi, A., \& Aceto, P. (2016). Fear of missing out (FOMO) is associated with activation of the right middle temporal gyrus during inclusion social cue. Computers in Human Behavior, 61, 516-521. https://doi.org/10.1016/j.chb.2016.03.072

Lamers, S. M. A., Bolier, L., Westerhof, G. J., Smit, F., \& Bohlmeijer, E. T. (2012). The impact of emotional well-being on long-term recovery and survival in physical illness: A meta-analysis. Journal of Behavioral Medicine, 35(5), 538547. https://doi.org/10.1007/s10865-011-9379-8

Larsen, R. (2009). The contributions of positive and negative affect to emotional well-being. Psihologijske Teme, $18(2), 247-266$.

Lee, E. B. (2015). Too much information: Heavy smartphone and Facebook utilization by African American young adults. Journal of Black Studies, 46(1), 44-61. https://doi.org/10.1177/0021934714557034

Lee, S., Kim, H. J., Choi, H. G., \& Yoo, Y. S. (2018). Smartphone addiction and interpersonal competence of nursing students. Iranian Journal of Public Health, 47(3), 342-349. http://ijph.tums.ac.ir/index.php/ijph/article/view/12680

Lee, Y.-K., Chang, C.-T., Lin, Y., \& Cheng, Z.-H. (2014). The dark side of smartphone usage: Psychological traits, compulsive behavior and technostress. Computers in Human Behavior, 31, 373-383.

https://doi.org/10.1016/J.CHB.2013.10.047

Lemola, S., Perkinson-Gloor, N., Brand, S., Dewald-Kaufmann, J. F., \& Grob, A. (2015). Adolescents' electronic media use at night, sleep disturbance, and depressive symptoms in the smartphone age. Journal of Youth and Adolescence, 44(2), 405-418. https://doi.org/10.1007/s10964-014-0176-x

Lepp, A., Barkley, J. E., \& Karpinski, A. C. (2014). The relationship between cell phone use, academic performance, anxiety, and satisfaction with life in college students. Computers in Human Behavior, 31, 343-350.

https://doi.org/10.1016/j.chb.2013.10.049

Lepp, A., Li, J., \& Barkley, J. E. (2016). College students' cell phone use and attachment to parents and peers. Computers in Human Behavior, 64, 401-408. https://doi.org/10.1016/j.chb.2016.07.021 
Lin, Y.-H., Chang, L.-R., Lee, Y.-H., Tseng, H.-W., Kuo, T. B. J., \& Chen, S.-H. (2014). Development and validation of the Smartphone Addiction Inventory (SPAI). PLOS ONE, 9(6), Article e98312.

https://doi.org/10.1371/journal.pone.0098312

Milyavskaya, M., Saffran, M., Hope, N., \& Koestner, R. (2018). Fear of missing out: Prevalence, dynamics, and consequences of experiencing FOMO. Motivation and Emotion, 42(5), 725-737. https://doi.org/10.1007/s11031018-9683-5

Mîndrilă, D. (2010). Maximum likelihood (ML) and diagonally weighted least squares (DWLS) estimation procedures: A comparison of estimation bias with ordinal and multivariate non-normal data. International Journal for Digital Society, 1(1), 60-66. https://doi.org/10.20533/ijds.2040.2570.2010.0010

Nie, N. H. (2001). Sociability, interpersonal relations, and the Internet: Reconciling conflicting findings. American Behavioral Scientist, 45(3), 420-435. https://doi.org/10.1177/00027640121957277

Oberst, U., Wegmann, E., Stodt, B., Brand, M., \& Chamarro, A. (2017). Negative consequences from heavy social networking in adolescents: The mediating role of fear of missing out. Journal of Adolescence, 55, 51-60. https://doi.org/10.1016/j.adolescence.2016.12.008

Ofcom. (2018). A decade of digital dependency. https://www.ofcom.org.uk/about-ofcom/latest/features-andnews/decade-of-digital-dependency

Ööpik, P., Aluoja, A., Kalda, R., \& Maaroos, H.-I. (2006). Screening for depression in primary care. Family Practice, 23(6), 693-698. https://doi.org/10.1093/fampra/cml052

Orben, A. (2020). Teenagers, screens and social media: A narrative review of reviews and key studies. Social Psychiatry and Psychiatric Epidemiology, 55(4), 407-414. https://doi.org/10.1007/s00127-019-01825-4

Oswald, A. J., Proto, E., \& Sgroi, D. (2015). Happiness and productivity. Journal of Labor Economics, 33(4), 789-822. https://doi.org/10.1086/681096

Panova, T., \& Carbonell, X. (2018). Is smartphone addiction really an addiction? Journal of Behavioral Addictions, 7(2), 252-259. https://doi.org/10.1556/2006.7.2018.49

Poushter, J., Bishop, C., \& Chwe, H. (2018). Social media use continues to rise in developing countries but plateaus across developed ones. Pew Research Center. https://www.pewresearch.org/global/2018/06/19/social-media-usecontinues-to-rise-in-developing-countries-but-plateaus-across-developed-ones/

Przybylski, A. K., Murayama, K., DeHaan, C. R., \& Gladwell, V. (2013). Motivational, emotional, and behavioral correlates of fear of missing out. Computers in Human Behavior, 29(4), 1841-1848.

https://doi.org/10.1016/J.CHB.2013.02.014

Raudlam, M. (2018). IImajäämishirmu (FoMO) küsimustiku adapteerimine ja valideerimine eesti keelde [Adaptation and validation of Estonian fear of missiong out (FoMO) scale; Unpublished Master's thesis, University of Tartu, Tartu, Estonia].

Reer, F., Tang, W. Y., \& Quandt, T. (2019). Psychosocial well-being and social media engagement: The mediating roles of social comparison orientation and fear of missing out. New Media \& Society, 21(7), 1486-1505.

https://doi.org/10.1177/1461444818823719

Rosseel, Y. (2012). Lavaan: An R package for structural equation modeling. Journal of Statistical Software, 48(2). https://doi.org/10.18637/jss.v048.i02

Rotondi, V., Stanca, L., \& Tomasuolo, M. (2017). Connecting alone: Smartphone use, quality of social interactions and well-being. Journal of Economic Psychology, 63, 17-26. https://doi.org/10.1016/j.joep.2017.09.001 
Rozgonjuk, D., Kattago, M., \& Täht, K. (2018). Social media use in lectures mediates the relationship between procrastination and problematic smartphone use. Computers in Human Behavior, 89, 191-198.

https://doi.org/10.1016/j.chb.2018.08.003

Rozgonjuk, D., Levine, J. C., Hall, B. J., \& Elhai, J. D. (2018). The association between problematic smartphone use, depression and anxiety symptom severity, and objectively measured smartphone use over one week. Computers in Human Behavior, 87, 10-17. https://doi.org/10.1016/j.chb.2018.05.019

Rozgonjuk, D., Rosenvald, V., Janno, S., \& Täht, K. (2016). Developing a shorter version of the Estonian Smartphone Addiction Proneness Scale (E-SAPS18). Cyberpsychology: Journal of Psychosocial Research on Cyberspace, 10(4), Article 4. https://doi.org/10.5817/CP2016-4-4

Rozgonjuk, D., Saal, K., \& Täht, K. (2018). Problematic smartphone use, deep and surface approaches to learning, and social media use in lecture. International Journal of Environmental Research and Public Health, 15(1), Article 92. https://doi.org/10.3390/ijerph15010092

Samaha, M., \& Hawi, N. S. (2016). Relationships among smartphone addiction, stress, academic performance, and satisfaction with life. Computers in Human Behavior, 57, 321-325. https://doi.org/10.1016/J.CHB.2015.12.045

Schreiber, J. B., Nora, A., Stage, F. K., Barlow, E. A., \& King, J. (2006). Reporting structural equation modeling and confirmatory factor analysis results: A review. The Journal of Educational Research, 99(6), 323-338.

https://doi.org/10.3200/JOER.99.6.323-338

Scott, H., \& Woods, H. C. (2018). Fear of missing out and sleep: Cognitive behavioural factors in adolescents' nighttime social media use. Journal of Adolescence, 68, 61-65. https://doi.org/10.1016/j.adolescence.2018.07.009

Smetaniuk, P. (2014). A preliminary investigation into the prevalence and prediction of problematic cell phone use. Journal of Behavioral Addictions, 3(1), 41-53. https://doi.org/10.1556/JBA.3.2014.004

Statistics Estonia. (2018). Eesti statistika kvartalikiri. 2/18. Quarterlybulletin of statistics Estonia. https://www.stat.ee/publication-2018_quarterly-bulletin-of-statistics-estonia-2-18

Takahashi, D. (2018, September 11). Newzoo: Smartphone users will top 3 billion in 2018, hit 3.8 billion by 2021. Venture Beat. https://venturebeat.com/2018/09/11/newzoo-smartphone-users-will-top-3-billion-in-2018-hit-3-8billion-by-2021/

Tandoc, E. C. Jr., Ferrucci, P., \& Duffy, M. (2015). Facebook use, envy, and depression among college students: Is facebooking depressing? Computers in Human Behavior, 43, 139-146. https://doi.org/10.1016/j.chb.2014.10.053

Thomée, S., Härenstam, A., \& Hagberg, M. (2011). Mobile phone use and stress, sleep disturbances, and symptoms of depression among young adults - A prospective cohort study. BMC Public Health, 11, Article 66. https://doi.org/10.1186/1471-2458-11-66

Tsai, H.-y. S., Hsu, P.-J., Chang, C.-L., Huang, C.-C., Ho, H.-F., \& LaRose, R. (2019). High tension lines: Negative social exchange and psychological well-being in the context of instant messaging. Computers in Human Behavior, 93, 326-332. https://doi.org/10.1016/j.chb.2018.12.034

Twenge, J. M. (2019). Stop debating whether too much smartphone time can hurt teens, and start protecting them. Time. https://time.com/collection/davos-2020-mental-health/5555737/smartphone-mental-health-teens/

Vahedi, Z., \& Saiphoo, A. (2018). The association between smartphone use, stress, and anxiety: A meta-analytic review. Stress and Health, 34(3), 347-358. https://doi.org/10.1002/smi.2805 
Vanden Abeele, M. M. P., Antheunis, M. L., \& Schouten, A. P. (2016). The effect of mobile messaging during a conversation on impression formation and interaction quality. Computers in Human Behavior, 62, 562-569. https://doi.org/10.1016/j.chb.2016.04.005

Verduyn, P., Lee, D. S., Park, J., Shablack, H., Orvell, A., Bayer, J., Ybarra, O., Jonides, J., \& Kross, E. (2015). Passive Facebook usage undermines affective well-being: Experimental and longitudinal evidence. Journal of Experimental Psychology: General, 144(2), 480-488. https://doi.org/10.1037/xge0000057

Verduyn, P., Ybarra, O., Résibois, M., Jonides, J., \& Kross, E. (2017). Do social network sites enhance or undermine subjective well-being? A critical review. Social Issues and Policy Review, 11(1), 274-302.

https://doi.org/10.1111/sipr.12033

Wegmann, E., Oberst, U., Stodt, B., \& Brand, M. (2017). Online-specific fear of missing out and Internet-use expectancies contribute to symptoms of Internet-communication disorder. Addictive Behaviors Reports, 5, 33-42. https://doi.org/10.1016/j.abrep.2017.04.001

Wolniewicz, C. A., Rozgonjuk, D., \& Elhai, J. D. (2020). Boredom proneness and fear of missing out mediate relations between depression and anxiety with problematic smartphone use. Human Behavior and Emerging Technologies, 2(1), 61-70. https://doi.org/10.1002/hbe2.159

Wolniewicz, C. A., Tiamiyu, M. F., Weeks, J. W., \& Elhai, J. D. (2018). Problematic smartphone use and relations with negative affect, fear of missing out, and fear of negative and positive evaluation. Psychiatry Research, 262, 618-623. https://doi.org/10.1016/j.psychres.2017.09.058

World Health Organization. (2019). Guidelines on physical activity, sedentary behaviour and sleep for children under 5 years of age. https://apps.who.int/iris/handle/10665/311664

World Medical Association. (2013). World Medical Association declaration of Helsinki: Ethical principles for medical research involving human subjects. JAMA, 310(20), 2191-2194.

https://doi.org/10.1001/jama.2013.281053

Xie, X., Wang, Y., Wang, P., Zhao, F., \& Lei, L. (2018). Basic psychological needs satisfaction and fear of missing out: Friend support moderated the mediating effect of individual relative deprivation. Psychiatry Research, 268, 223-228. https://doi.org/10.1016/j.psychres.2018.07.025 


\title{
Correspondence to:
}

Nino Gugushvili

Faculty of Psychology and Neuroscience, Maastricht University

Universiteitssingel 40

Maastricht, 6229

The Netherlands

Email: n.gugushvili(at)maastrichtuniversity.nl

Editorial record: First submission received on April 2, 2019. Revisions received on February 7, 2020 and April 20, 2020. Accepted for publication on May 4, 2020.

Editor in charge: David Smahel

\begin{abstract}
About Authors
Nino Gugushvili is a PhD student in psychology at the University of Tartu, Estonia, and at the Maastricht University, the Netherlands. Her research interests include digital communication technologies and their impact on subjective well-being.

Karin Täht, Ph.D., is a research fellow (psychometrics) in the Department of Psychology at the University of Tartu, Estonia. Her research has mainly been connected with educational psychology.

Dmitri Rozgonjuk, Ph.D., mainly works in the area of cyberpsychology, aiming to understand the interplay between digital technology use and human behavior, feeling, and thinking. He is also interested in personality and educational psychology, and research methods. He is currently a postdoctoral research fellow at the Department of Molecular Psychology at Ulm University in Germany, and a senior specialist in education studies at the Institute of Mathematics and Statistics at University of Tartu in Estonia.
\end{abstract}

Maris Raudlam, M.A., was a master student in Psychology at the University of Tartu, Estonia. This study is based on the data collected for her master thesis project.

Robert A. C. Ruiter is a professor in applied social psychology at Maastricht University. His research focuses on the broad application of findings and theory in social psychology and cognitive neuroscience in understanding and changing human behavior in different applied settings, including health promotion, disease prevention, safety management, and sustainable environment.

Philippe Verduyn is an associate professor in social psychology at Maastricht University. He conducts research on emotion dynamics, emotion regulation and social network sites. 